\title{
Método de combinação de dados de precipitação estimados por satélite e medidos em pluviômetros para a modelagem hidrológica
}

\section{Merging rainfall gauges and satellite rainfall data for hydrology modeling}

\author{
Karena Quiroz Jiménez ${ }^{1}$; Walter Collischonn
}

${ }^{1}$ Doutoranda em Recursos Hídricos e Saneamento Ambiental, IPH-UFRGS, karenaquiroz@gmail.com

${ }^{2}$ Professor do Instituto de Pesquisas Hidraulicas da Universidade Federal do Rio Grande do Sul, rua Bento Gonçalves, 9500, Porto Alegre, RS. collischonn@iph.ufrgs.br

Recebido: 26/05/14 - Revisado: 01/09/14 - Aceito: 10/10/14

\begin{abstract}
RESUMO
No presente trabalho é proposto um método de interpolação denominado CHUVSAT para ser avaliado como dado de entrada a um modelo hidrológico. Esse método calcula campos de chuva em forma de grade regular combinando chuva obtida por pluviômetros com dados de chuva por satélite. O CHUVSAT está baseado em um cálculo de médias ponderadas que considera a distância e o tipo de dado (pluviômetro ou satélite) como fonte de informação. Os dados de chuva de pluviômetros e de satélite foram obtidos da Agência Nacional de Águas (ANA) e do produto Tropical Rainfall Measuring Mission (TRMM), respectivamente. Os resultados foram avaliados comparando os hidrogramas calculados a partir de um modelo bidrológico distribuido com os hidrogramas observados em diferentes postos fluviométricos da bacia do Rio Tocantins. O desempenho do método CHUVSAT foi comparado ao desempenho do modelo bidrológico usando os dados do TRMM, e os dados de pluviometros da ANA. Os resultados mostraram que a qualidade da série de vazões calculadas usando CHUVSAT conseguiu melhores coeficientes de eficiência de Nash-Sutcliffe para as séries geradas pelas fontes da ANA e do TRMM em bacias com área de drenagem da ordem de $5.000 \mathrm{~km}^{2}$. Em bacias maiores os resultados de CHUVSAT foram semelhantes aos obtidos utilizando apenas os dados de chuva observados em pluviômetros, enquanto os resultados utilizando dados de satélite foram inferiores. Conclui-se que a combinação de dados de satélite e pluviômetros tem potencial para aplicações hidrológicas, com ênfase na previsão de vazões em rios de grande porte.
\end{abstract}

Palavras Chave: Pluviometria. Interpolação de dados de chuva. Estimativa de chuva por satélite. TRMM. Simulação bidrológica.

\begin{abstract}
In this work, an interpolation method called CHUVSAT was proposed as input data to a bydrological model. This method calculates fields of precipitation in the form of a regular grid obtained by combining rainganges with satellite rainfall data. CHUVSAT is based on a calculation of weighted average that considers the distance and the type of data (raingange or satellite) as a source of information. The rainfall data from rainganges and satellite were obtained from the National Water Agency (ANA) of Brazil and the Tropical Rainfall Measuring Mission (TRMM), respectively. The results were evaluated by comparing the calculated hydrograph from a distributed bydrological model with observed bydrographs at different streamflow stations in the Tocantins River basin. The performance of the method using CHUVSAT was compared to the performance of the hydrological model using only the data from TRMM and $A N A$. The results showed that the quality of the series of streamflows calculated using CHUVSAT was generally better for series generated by the sources of ANA and TRMM in basins with a drainage area of around 5,000 $\mathrm{km}^{2}$. In larger basin results using the combined method CHUVS AT were similar to those obtained using only the data observed in rainfall ganges, while results using satellite data were less good. We conclude that the combination of satellite rainfall and rainganges has a potential for hydrological applications such as streamflow forecasting for large rivers.
\end{abstract}

Keywords: Precipitation rate. Interpolation of rainfall data. Satellite rainfall estimation. TRMM. Hydrologic simulation. 


\section{INTRODUÇÃO}

A precipitação é, possivelmente, a principal variável para a caracterização hidrológica de uma região. Além disso, a precipitação é, também, o principal dado de entrada em modelos hidrológicos chuva-vazão. Normalmente, a estimativa da chuva que atinge uma bacia hidrográfica é realizada utilizando medições pontuais realizadas com pluviômetros ou pluviógrafos. Os dados de chuva de pluviômetros, válidos para um ponto, são utilizados para estimar a chuva média sobre toda a bacia hidrográfica, utilizando métodos de interpolação. Contudo, a quantificação da chuva é difícil devido a sua variabilidade espacial e temporal (SUMNER, 1998) e a qualidade da estimativa é fortemente dependente da densidade espacial de postos pluviométricos, medida em número de postos por $\mathrm{km}^{2}$, ou o inverso da densidade, que é a área média $\left(\mathrm{em} \mathrm{km}^{2}\right)$ por posto pluviométrico.

Em muitas regiões do Mundo, as densidades mínimas por estações são inferiores aos valores recomendados pela OMM, que são: $900 \mathrm{~km}^{2}$ por estação em regiões costeiras; 250 $\mathrm{km}^{2}$ por estação em áreas montanhosas; $575 \mathrm{~km}^{2}$ por estação em regiões com morros e colinas no interior; e $20 \mathrm{~km}^{2}$ por estação em áreas urbanas (OMM, 1994). Muitas vezes a quantidade de postos pluviométricos tende a ser insuficiente para aplicações de técnicas de modelagem hidrológica, climática ou previsão de vazões. O desenvolvimento das redes de monitoramento em algumas dessas regiões, revelam que o número de postos pluviométricos não mostrou crescimento expressivo nas últimas décadas e, em alguns casos, até ocorreu um declínio na operação, como na bacia do rio da Prata (SU et al., 2009) e nas bacias do Sul da África (HUGHES, 2006).

Diferentemente dos pluviômetros, os radares meteorológicos permitem estimar a precipitação de forma razoavelmente contínua no tempo e no espaço. Em alguns casos, estes dados podem complementar a informação dos pluviômetros. Porém, a estimativa de precipitação por radar é baseada em medições indiretas e têm diversas fontes de incerteza, como a calibração do hardware, a orientação apropriada da antena de controle de radar, a atenuação devido a umidade ou neve, os ruídos não meteorológicos e a estimativa dos parâmetros da chamada função Z-R, que relaciona a refletividade e a intensidade da precipitação (EINFALT; MICHAELIDES, 2008).

No Brasil, a cobertura espacial dos radares para a estimativa da precipitação ainda é limitada. Por este motivo, nos últimos anos surgiu o interesse pela estimativa da precipitação a partir de sensores instalados em satélites.

A estimativa da precipitação por satélite está baseada na medição de radiação eletromagnética refletida ou emitida pelas nuvens e pela chuva, especialmente nas faixas de comprimento de onda correspondente ao infravermelho, micro-ondas e visível. A partir do final da década de 90 também começaram a disponibilizar dados de sensores de radar, colocados a bordo de satélites. Em geral, para obter estimativas de precipitação de uma determinada região por sensoriamento remoto, os dados de diferentes sensores são combinados através de algoritmos.

Os primeiros algoritmos desenvolvidos foram baseados na relação entre a temperatura no topo das nuvens e a intensidade da precipitação. Para estimar a temperatura no topo das nuvens podem ser utilizados sensores na faixa espectral correspondente ao infravermelho. Os sensores que percebem radiação na faixa de comprimento de onda de 10,6 a 12,6 $\mu \mathrm{m}$ é o resultado da absorção emitida sobre a superfície dos topos das nuvens para o espaço. A premissa física de um sistema de nuvens que gera precipitação ocorre porque existe uma relação entre a temperatura de topo do sistema de nuvens e em função da altura destas. Desta forma, os topos de nuvens mais altos e mais frios correspondem às nuvens mais espessas e normalmente são as que mais precipitam (SCOFIELD; VENDRAME, 2003; KIDD, 2001). A partir das premissas físicas, técnicas de estimação de precipitação pela banda do infravermelho foram desenvolvidas, por exemplo, o Hidroestimador (VICENTE, 1998).

Além da radiação na faixa do infravermelho, muitos algoritmos de estimativa de precipitação por sensoriamento remoto utilizam atualmente, dados de sensores de radiação na faixa de micro-ondas (10 a $150 \mathrm{GHz}$ ) e vem do resultado da radiação reemitida da Terra para o espaço (SCOFIELD; VENDRAME, 2003). Esta energia interage com os hidrometeoros mediante os processos de absorção e espalhamento, atravessando as nuvens que inferem nas propriedades físicas amostradas. Os sensores de radiômetros passivos nessa banda respondem à presença de gotas de chuva e partículas de gelo presentes nas nuvens, ou seja, evidências físicas mais diretas da precipitação do que a temperatura do topo da nuvem (HOU et al., 2008). Sensores de micro-ondas passivos colocados a bordo de satélites em órbita polar, normalmente possuem resolução espacial baixa, da ordem de quilômetros.

Ao longo dos últimos 20 anos, e desde que o satélite Tropical Rainfall Measurement Mission (TRMM) foi lançado ao espaço, diversos algoritmos de estimativa de precipitação foram criados. Esses algoritmos estão baseados na observação multiespectral desde diversos satélites de diferentes órbitas. Podem ser citados como exemplo os produtos Climate Prediction Center Morphing - CMORPH (JOYCE et al., 2004); TRMM Multisatellite Precipitation Analysis - TMPA TRMM (HUFFMAN et al., 2007) e Precipitation Estimation from Remotely Sensed Information using Artificial Neural Network - PERSLANN (HONG et al., 2004), entre outros.

Considerando a variedade de produtos de estimativa de chuva por satélite, atualmente existem trabalhos apresentando diversas análises que buscam identificar a potencialidade dos diferentes produtos em áreas específicas, ou em todo o globo. No contexto da América do Sul, destacam-se os trabalhos de Scofield e Vendrame (2003); Collischonn et al. (2007); Saldanha et al. (2007); Araújo e Guetter (2007); Collischonn et al. (2008); Su et al. (2008); Dinku et al. (2010); Pereira Filho et al. (2010); Buarque et al. (2011); Getirana et al. (2011); Quiroz et al. (2011); Quiroz et al. (2013).

Erros sistemáticos foram observados em regiões em que a chuva ocorre sob influência orográfica. Nestas regiões a chuva é produzida por nuvens relativamente baixas e quentes, o que leva a uma subestimativa quando a chuva estimada por satélite é comparada com campos de chuva observada por pluviômetros instalados em Terra (HUGHES, 2006; DINKU et al., 2010, STAMPOULIS; ANAGNOSTOU, 2012; SALDANHA et al., 2007). Esta tendência à subestimativa em regiões de forte orografia também foi observada quando as estimativas 
de chuva de satélite foram utilizadas como dado de entrada para modelos hidrológicos, resultando em uma subestimativa nas séries de vazão calculada (QUIROZ et al., 2011; NIKOLOPOULOS et al., 2013; BEHRANGI et al., 2011; PAN et al, 2010; GETIRANA et al., 2011). No entanto, em regiões mais planas do Brasil, no sul da bacia do rio Amazonas, precipitação do TRMM mostrou-se adequada como variável de entrada aos modelos hidrológicos, em simulação diária, como na bacia do rio Tapajós (COLLISCHONN et al., 2008) e alguns rios tributários do rio Amazonas (PAIVA et al., 2011). Mais para o Sudeste de Brasil, também os resultados se mostraram promissores como na Bacia do rio da Prata (SU, et al., 2008) e na bacia do Rio Iguaçu (ARAÚJO et al., 2007).

Diversos trabalhos mostram que os erros aleatórios dependem fortemente da escala de tempo em que é feita a avaliação. Tipicamente, as melhores correlações entre dados observados em pluviômetros e dados estimados por satélite, são obtidas quando a comparação é feita integrando os dados em intervalos de tempo mensais ou anuais, como em Pereira et al. (2010).

Considerando estas incertezas, acredita-se que a melhor forma de utilizar as estimativas de precipitação por sensoriamento remoto, é através de uma estratégia de combinação entre os dados de pluviômetros e as estimativas por satélite. Neste sentido, possivelmente o exemplo mais conhecido seja o próprio produto TRMM-3B42, que é uma estimativa de chuva corrigida da base de dados do Projeto Climatológico de Precipitação Global (GPCP) na forma descrita em Huffman et al. (2007). Esse produto é fornecido pela NASA, via internet, em escala temporal de três em três horas para escala espacial de $0,25^{\circ}$, no entanto, ele é fornecido com um atraso de três meses, impossibilitando seu uso para algumas aplicações hidrológicas imediatas.

Uma proposta de metodologia de combinação de dados de satélite com pluviômetros mais recente, foi apresentada por Rozante et al. (2010). Estes autores desenvolveram uma técnica de combinação de dados para a América do Sul, que foi denominada MERGE, e que é baseada em estimativas de chuva por satélite e nos dados observados em pluviômetros do Centro de Previsão de Tempo e Estudos Climáticos (CPTEC); Instituto Nacional de Pesquisas Espaciais (INPE) e das estações climáticas de Global Telecommunications System (GTS). As estimativas de chuva por satélite utilizadas no MERGE, são o resultado da aplicação do algoritmo TRMM-3B42RT por Huffman et al., (2007), que estão disponíveis em tempo quase real (com apenas algumas horas de atraso). O método MERGE tem a vantagem de utilizar uma grande quantidade de pluviômetros localizados no Brasil (ROZANTE et al., 2010), o que contribui para melhorar a qualidade da estimativa da chuva nesta região. Além disso, as estimativas de chuva do MERGE podem ser utilizadas em alguns casos de hidrologia operacional, porque são disponibilizadas com apenas 24 horas de atraso.

Outro trabalho similar, de combinação de estimativas de chuva por satélite com dados de pluviômetros, é apresentado por Vila et al. (2009), onde uma combinação linear ponderada de duas diferentes distorções da estimativa da chuva por satélite, na forma aditiva e proporcional, é efetuada para toda América do Sul.
Mais recentemente, Clarke e Buarque (2013) exploraram a combinação de dois produtos de chuva por satélite, CMORPH e TRMM-3B42, em escala anual por meio de uma análise multivariada e modelos geoestatísticos paramétricos sobre a bacia do rio Tocantins. Os resultados mostraram que a combinação de ambas as fontes, podem ser variáveis preditoras em locais onde não se têm dados observados. Woldemeskel et al. (2013) na Austrália exploraram um método de combinação entre pluviômetros e chuva por satélite TRMM-3B42 em escala mensal. A técnica de combinação foi baseada no método de interpolação ponderada pela distância, e os resultados mostraram que a técnica de combinação melhorou a estimativa da precipitação, sobre algumas regiões da Austrália.

As técnicas de combinação entre precipitação por satélite e postos observados em Terra, podem ser de interesse cientifico e prático na área de hidrologia ou climatologia. $\mathrm{O}$ objetivo do presente estudo aborda uma nova proposta de método de combinação de dados de chuva, medidos em pluviômetros com dados estimados por satélite em tempo quase real TRMM-RT, em escala temporal diária e em escala espacial de $0,25^{\circ}$. Os resultados do método são avaliados, empregando uma metodologia de transformação de chuva em vazão, utilizando um modelo hidrológico e comparando as séries temporais de vazões calculadas, com as séries temporais de vazões observadas em diferentes seções de rios da bacia do rio Tocantins.

\section{ÁREA DE ESTUDO}

A área de estudo foi realizada na bacia do rio Tocantins, na região Norte de Brasil. A área de drenagem do rio Tocantins é de, aproximadamente, $300.000 \mathrm{~km}^{2}$ até o local do posto fluviométrico Descarreto, que está localizado próximo à cidade de Imperatriz, no Maranhão, como mostrado na Figura 1. As altitudes da bacia variam desde 115 a 1.670 metros, com as maiores altitudes no sul. A bacia foi escolhida porque apresenta áreas com monitoramento pluviométrico relativamente deficiente, ou seja, com baixa densidade de postos pluviométricos por $\mathrm{km}^{2}$. Além disso, a bacia é importante do ponto de vista econômico, com a presença de várias grandes usinas hidrelétricas, como a UHE Estreito, e diversas cidades como, a cidade de Imperatriz, localizadas próximas ao rio principal.

\section{DADOS E METODOLOGIA}

Dados de chuva estimados por satélite e observados em uma rede de pluviômetros foram combinados através de uma metodologia de interpolação que considera, ao mesmo tempo, os dois tipos de informação. Posteriormente, os dados de chuva interpolados foram utilizados como dados de entrada para um modelo hidrológico distribuído, e os hidrogramas de vazão calculados, foram comparados com os hidrogramas observados em diversos postos fluviométricos, distribuídos em toda a bacia do rio Tocantins. Os itens que seguem descrevem a base de dados utilizada, a metodologia de interpolação e o modelo hidrológico adotado. 
Por último, os dados de temperatura média do ar, umidade relativa, velocidade do vento e pressão atmosférica e insolação, foram obtidos de 15 estações climatológicas do local. Todos os dados climáticos e de vazão observada para o processo de simulação hidrológica, foram obtidos da base de dados da Agencia Nacional de Águas (ANA).

\section{Técnica de combinação das fontes de precipita- ção}

A metodologia de combinação de dados de satélite e de pluviômetros, proposta no presente trabalho, foi denominada CHUVSAT e é baseada numa técnica de interpolação ponderada pela distância. Considera-se que a informação de chuva dos pluviômetros está disponível em pontos distribuídos de forma aleatória

Foram utilizados dados de postos pluviométricos do banco de dados da Agência Nacional de Águas (ANA). Esses dados de precipitação fornecidos pela ANA são consistidos de acordo com o padrão estabelecido pela ANEEL (1999). Na área de estudo foram considerados 293 postos pluviométricos, tanto dentro como fora da bacia do rio Tocantins e, apresentam no máximo 30\% de falhas. Na região de estudo existem 283 postos com menos de $5 \%$ de falhas nos dados, oito postos com $6 \%$ a $20 \%$ de falhas e dois postos com $21 \%$ a $30 \%$ de falhas.

Entre os vários tipos de produtos de estimativa de chuva por satélite produzido pelo TMPA-TRMM, para este trabalho foi escolhido o produto TRMM-3B42RT, produtos de precipitação derivados do satélite TRMM e outros satélites.

Os principais instrumentos do satélite TRMM são: o imageador de micro-ondas (TMI), radar de precipitação (PR), radiômetros de radiação visível e infravermelha (VIRS). A cobertura dos produtos do TRMM-TMPA depende dos dados dos sensores de micro-onda, coletados por vários satélites em órbita baixa, incluindo o TMI e dados dos sensores de satélites geoestacionários.

O produto TRMM-3B42RT é obtido da combinação de diversas fontes multiespectrais sem correção de dados observados em Terra e sem uso dos dados do Radar (PR). Esse produto fornece estimativas da precipitação a cada três horas, com uma resolução espacial de $0,25^{\circ}$ e é disponibilizado em tempo quase atual, isto é, com cerca de 9 horas de defasagem. Os dados do TRMM-3B42RT estão disponíveis em todo o Globo, na região entre as latitudes $50^{\circ} \mathrm{N}$ e $50^{\circ} \mathrm{S}$, e são fornecidos em arquivos individuais de três em três horas (oito arquivos por cada 24 horas).

$\mathrm{Na}$ aplicação descrita aqui, a chuva diária é obtida agregando os arquivos individuais desde as 15:00 UTC horas (período de 12:00-15:00) de um dia prévio até às 12:00 UTC horas (período de 09:00-12:00) do dia atual, de forma a corresponder, da melhor forma possível, aos dados normalmente coletados no Brasil em pluviômetros de observação manual.

Os postos fluviométricos com a disponibilidade de dados de vazão observada são contabilizados em 41. Do total desses postos, nove são afetados pela operação dos reservatórios de usinas e cinco são locais das usinas, as quais não serão consideradas nesse trabalho. Portanto, 27 estações com vazões a)

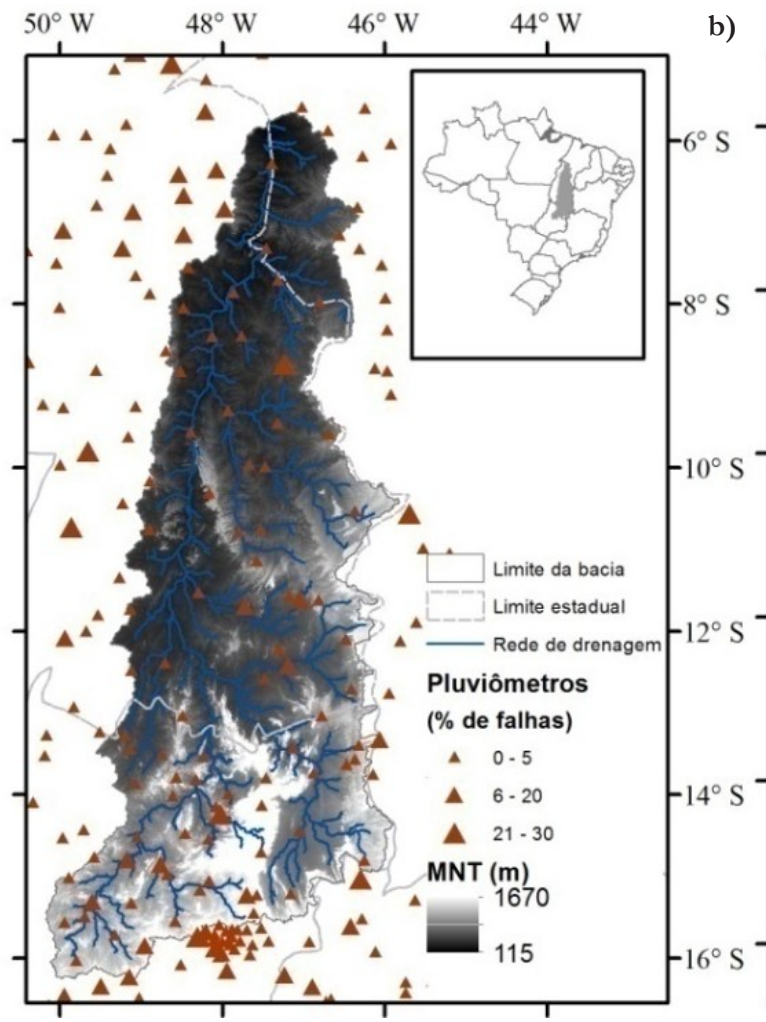

b)

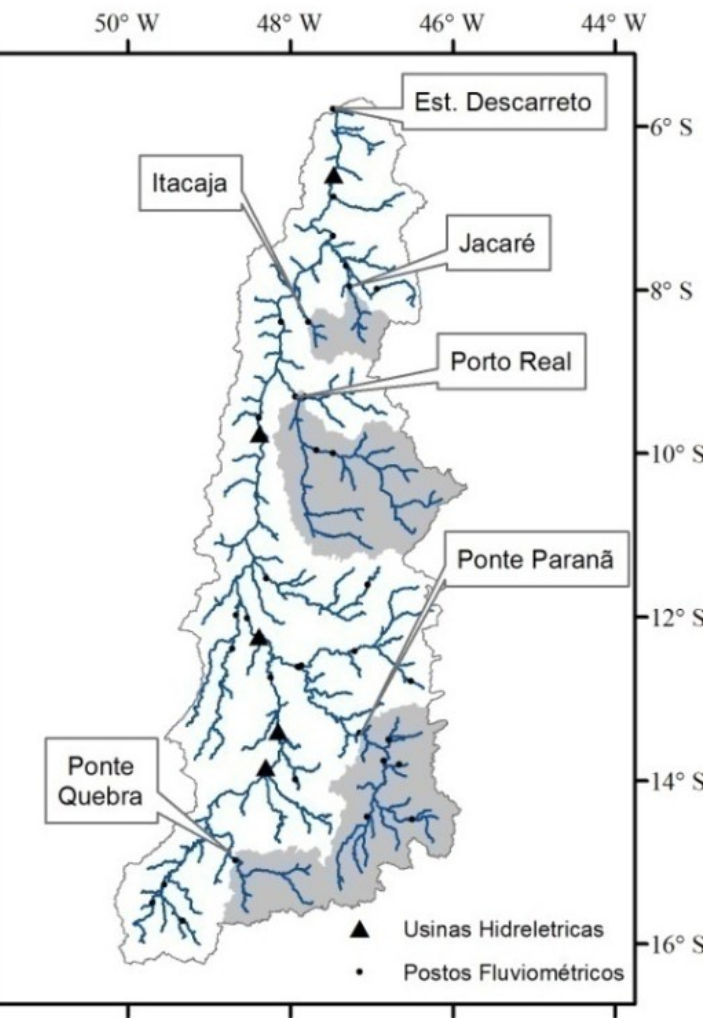

Figura 1 - a) Localização da bacia do rio Tocantins com a distribuição pluviométrica e o relevo topográfico; b) Localização dos pontos de controle hidrológica com a área e rede de drenagem das principais sub-bacias tributárias 
Tabela 1 - Postos fluviométricos sobre a bacia do Rio Tocantins.

\begin{tabular}{|c|c|c|c|c|}
\hline Id & Código & Nome & Nome do Rio & $\begin{array}{c}\text { Área de } \\
\text { drenagem } \\
\left(\mathrm{km}^{2}\right)\end{array}$ \\
\hline 1 & 20100000 & Jaragua & Rio das Almas & 1.983 \\
\hline 2 & 20250000 & Ceres & Rio das Almas & 10.668 \\
\hline 3 & 20200000 & Uruana & Rio de Uru & 3.695 \\
\hline 4 & 20050000 & Ponte Quebra Linha & Maranhão & 11.275 \\
\hline 5 & 20950000 & Ponte rio preto & Rio Preto & 881 \\
\hline 6 & 21300000 & Alvorada Norte & Rio Corrente & 3.787 \\
\hline 7 & 21560000 & Fazenda Veneza & Rio São Domingos & 2.859 \\
\hline 8 & 21220000 & Flores de Goiás & Rio Paranã & 7.288 \\
\hline 9 & 21500000 & Nova Roma & Rio Paranã & 22.774 \\
\hline 10 & 21600000 & Ponte Paranã & Rio Paranã & 29.791 \\
\hline 11 & 21650000 & Montante Barra Palma & Rio Paranã & 40.526 \\
\hline 12 & 21900000 & Paranã & Rio Paranã & 58.568 \\
\hline 13 & 21850000 & Rio da palma & Rio Palma & 12.992 \\
\hline 14 & 21890000 & Barra Palma & Rio Palma & 17.989 \\
\hline 15 & 22100000 & Colonha & Rio Santa Teresa & 8.741 \\
\hline 16 & 22150000 & Jacinto & Rio Santa Teresa & 13.938 \\
\hline 17 & 22190000 & Porto Alegre & Rio Manuel Alves & 1.803 \\
\hline 18 & 22250000 & Fazenda Lobeira & Rio Manuel Alves & 14.517 \\
\hline 19 & 23150000 & Itacaja & Rio Manuel Alves & 2.849 \\
\hline 20 & 23220000 & Cachoeira & Rio Manuel Alves & 2.933 \\
\hline 21 & 23250000 & Goiatins & Rio Manuel Alves & 10.098 \\
\hline 22 & 22680000 & Jatobá & Rio do Sono & 17.076 \\
\hline 23 & 22700000 & Novo Acordo & Rio do Sono & 18.187 \\
\hline 24 & 22900000 & Porto Real & Rio do Sono & 44.293 \\
\hline 25 & 22850000 & Dois irmãos & Rio Perdida & 9.546 \\
\hline 26 & 23230000 & Jacare & Rio Vermelho & 4.085 \\
\hline 27 & 23468000 & Fazenda Farinha & Rio Farinha & 5.176 \\
\hline- & 23700000 & Descarreto & Rio Tocantins & 299.109 \\
\hline
\end{tabular}

observadas são consideradas para a análise do método de combinação de precipitação sobre o modelo hidrológico, as mesmas que estão listadas na Tabela 1.

de satélite, está disponível sobre os pontos de uma grade regular. A partir destes dois tipos de informação, a precipitação em um local qualquer $(\mathrm{k})$ pode ser calculada por uma média ponderada dos valores dos postos pluviométricos $(\mathrm{P})$ e das estimativas de precipitação de satélite $(\mathbf{S})$, de acordo com a Equação 1:

$$
\widehat{\mathrm{P}}_{\mathrm{k}}^{\mathrm{t}}=\frac{\sum_{\mathrm{i}=1}^{\mathrm{np}} \mathrm{w}_{\mathrm{p}} \mathrm{P}_{\mathrm{i}}^{\mathrm{t}}}{\sum_{\mathrm{i}=1}^{\mathrm{np}} \mathrm{w}_{\mathrm{p}}+\sum_{\mathrm{j}=1}^{\mathrm{ns}} \mathrm{w}_{\mathrm{s}}}+\frac{\sum_{\mathrm{j}=1}^{\mathrm{ns}} \mathrm{w}_{\mathrm{s}} \mathrm{S}_{\mathrm{j}}^{\mathrm{t}}}{\sum_{\mathrm{i}=1}^{\mathrm{np}} \mathrm{w}_{\mathrm{p}}+\sum_{\mathrm{j}=1}^{\mathrm{ns}} \mathrm{w}_{\mathrm{s}}}
$$

onde, $\widehat{\mathrm{P}}_{\mathrm{k}}^{\mathrm{t}}$ é o valor da precipitação interpolada no intervalo de tempo $\mathrm{t}$ na posição $\mathrm{k}$; $\mathrm{np}$ é o número de postos pluviométricos utilizados na interpolação; ns é o número de pontos da grade da estimativa de chuva por satélite, utilizados na interpolação; $\mathrm{P}_{i}^{\mathrm{t}}$ é o valor da precipitação observada no pluviômetro $\mathbf{i}$, no interva'o de tempc $t$; $\mathrm{S}_{\mathrm{j}}^{\mathrm{t}}$ é o valor da precipitação de satélite na posição $\mathbf{j}$ no tempo $t$; $w_{p}$ é o ponderador aplicado aos dados dos pluviômetros e $\mathbf{W}_{\mathbf{s}}$ é o ponderador aplicado aos dados do satélite.

Os ponderadores $w_{p}$ e $w_{s}$ tem duas componentes, conforme apresentado nas equações 2 e 3 . O primeiro componente $(\alpha$ ou $\beta$ ) é um fator associado ao tipo de informação (pluviômetro ou satélite, respectivamente). O segundo componente do ponderador é um peso associado à distância, conforme as equações 2 e 3 :

$$
\begin{aligned}
& w_{p}=\alpha \frac{1}{d^{\gamma}} \\
& w_{s}=\beta \frac{1}{d^{\theta}}
\end{aligned}
$$

onde $w_{p}$ é o ponderador aplicado aos dados dos pluviômetros; $w_{s}$ é o ponderador aplicado aos dados do satélite; $\alpha$ é um peso associado com os dados dos pluviômetros; $\beta$ é um peso associado com os dados do satélite; $\mathrm{d}$ é a distância entre o ponto $\mathrm{k}$ em que é calculada a chuva e a posição do pluviômetro ou do ponto central de pixel da grade do satélite; $\gamma$ é o expoente da distância na ponderação dos dados de pluviômetros; e $\theta$ é o expoente da distância na ponderação dos dados de satélite.

Os valores de $\alpha, \beta, \gamma$ e $\theta$ são parâmetros do método de interpolação, que podem ser definidos com base em uma metodologia de calibração, que está descrita adiante no texto.

Conforme mostra a Figura 2, as informações de chuva de pluviômetros estão definidas em pontos aleatoriamente 
distribuídos, e as informações de chuva estimada por satélite são dadas em pontos regularmente dispostos em uma grade. A interpolação é realizada recalculando valores de precipitação para os pontos de grade, correspondentes às informações de chuva de satélite. Para calcular a estimativa corrigida de chuva em um ponto de grade, utilizando a equação 1, são utilizados apenas os dados dos pluviômetros e dos pontos de grade da imagem de satélite contidos dentro do círculo de raio $\mathrm{R}_{\max } \mathrm{em}$ torno do ponto, conforme mostra a Figura 2.

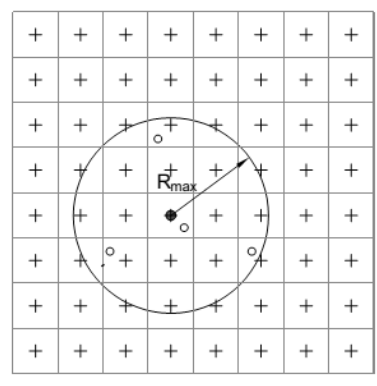

+Estimativa de chuva por satélite

- Precipitação observada por pluviômetro

- Local em que se deseja interpolar

Figura 2 - Representação esquemática da metodologia de CHUVSAT, os pluviômetros (representados pelo símbolo ${ }^{\circ}$ ) e estimativas de chuva por satélite (representadas pelo símbolo +)

O método de interpolação foi utilizado retirando-se um posto pluviométrico do conjunto de dados, e gerando a série temporal de precipitação para o ponto correspondente a este pluviômetro. Os valores estimados por interpolação foram, então, comparados aos valores da série observada no pluviômetro. Este procedimento foi repetido retirando cada um dos pluviômetros e gerando a série no local correspondente. Os valores de precipitação estimada por interpolação foram comparados com os valores de precipitação observada, e para cada conjunto de valores dos parâmetros $\alpha, \beta, \gamma$ e $\theta$ foi calculado um valor correspondente de uma função objetivo $F$, dada pela equação 4 :

$$
\text { Mínimo: } F=\frac{\sum_{i=1}^{n t}\left(p_{0}-p_{c}\right)^{2}}{\sum_{i=1}^{n t}\left(p_{0}-\overline{p_{0}}\right)^{2}}
$$

onde, nt é o numero de intervalo de tempo da série de precipitação, $p_{o}$ é o valor da precipitação observada e $p_{c}$ é o valor da precipitação estimada e $\overline{\mathrm{p}}_{\mathrm{o}}$ é a média dos nt valores da precipitação observada.

O procedimento foi repetido, com valores diferentes dos parâmetros $\alpha, \beta$, $\gamma$ e $\theta$, buscando o menor valor de F. Este procedimento seguiu o método de otimização Shuffled Complex

Tabela 2 - Limites máximos e mínimos dos parâmetros envolvidos do método de interpolação

\begin{tabular}{l|c|c|c|c}
\hline & $\begin{array}{c}\text { Alfa } \\
(\alpha)\end{array}$ & $\begin{array}{c}\text { beta } \\
(\boldsymbol{\beta})\end{array}$ & $\begin{array}{c}\text { gamma } \\
(\gamma)\end{array}$ & $\begin{array}{c}\text { teta } \\
(\boldsymbol{\theta})\end{array}$ \\
\hline Mínimo & 0,0 & 0,0 & 0,0 & 0,0 \\
Máximo & 40,0 & 40,0 & 5,0 & 5,0 \\
\hline
\end{tabular}

Evolution SCE-UA (DUAN et al., 1992; DINIZ et al., 1999). Os quatro valores ótimos dos parâmetros foram buscados dentro de limites pré-definidos, apresentados na Tabela 2.

\section{Rotina de Interpolação}

O método de interpolação combinada de chuva foi aplicado, após a interpolação dos seus parâmetros, gerando um novo campo de precipitação regular (denominado CHUVSAT) com resolução espacial de $0,25 \circ$, igual à resolução original do produto TRMM-3B42RT, para cada intervalo de tempo (dia), de acordo com o procedimento descrito a seguir.

1- Leitura dos parâmetros do método de interpolação $\alpha, \beta, \gamma$ e $\theta$.

2 - Abre um laço para o número total de intervalos de tempo desde it $=1, \ldots$ nt.

a -Abre um laço de posição $k=1, \ldots$ ns.

Cálculo de precipitação interpolada nos mesmos centros de grade da precipitação por satélite.

b- Busca dos postos pluviométricos dentro do raio $\mathrm{R}_{\text {máx }}$, quantificam-se os postos pluviométricos np; calculam-se os valores dos ponderadores tal qual foi definido na Eq. 2.

c - Busca dos centros de grade dentro do raio $\mathrm{R}_{\text {máx }}$, sem incluir a grade da posição $k$, quantificam-se os centros de grade ns; calculam-se os valores dos ponderadores tal qual foi definido na Eq. 3 .

e - Calcula-se a precipitação interpolada na posição $\mathrm{k}$ no intervalo de tempo it tal como foi definido na Eq. 1.

f - Fim de laço de interpolação da precipitação na posição $k$.

3 - Fim do laço do número total de intervalos de tempo nt.

Durante o processo de interpolação foram feitas as seguintes considerações:

1) quando existe um posto pluviométrico com valor no interior de um ponto de grade, o valor da chuva interpolado no ponto de grade é igual à chuva do pluviômetro;

2) quando não há nenhum posto pluviométrico dentro do raio máximo $\left(\mathrm{R}_{\text {máx }}\right)$, o valor da chuva corrigida no ponto de grade permanece igual ao valor original da estimativa por satélite.

\section{Modelo hidrológico distribuído MGB-IPH}

O Modelo de Grandes Bacias (MGB-IPH) é um modelo hidrológico distribuído, para bacias de grande escala e foi desenvolvido por Collischonn e Tucci (2001). Na sua versão mais recente, este modelo utiliza uma discretização da bacia em unidades irregulares, denominadas mini-bacias, que são definidas a partir de dados do relevo de um Modelo Digital de Elevação (FAN et al., 2009; FAN et al. 2010). As mini-bacias que compõem a bacia hidrográfica são subdivididas em Unidades de Resposta Hidrológicas (URH), que são áreas de comportamento hidrológico similar. O modelo é composto por módulos que 
calculam diferentes processos hidrológicos relevantes na transformação da chuva em vazão, como a interceptação, o balanço hídrico do solo, a geração do escoamento em cada mini-bacia, a evapotranspiração e a propagação da vazão através da rede de drenagem.

A cada intervalo de tempo a chuva é calculada em cada mini-bacia, considerando as coordenadas do centróide da mini-bacia, por meio de um método de interpolação. Quando os dados de precipitação estão disponíveis na forma de uma grade regular, a estimativa da precipitação em cada mini-bacia é obtida com base em uma média aritmética dos dados de precipitação de todos os pontos de grade, localizados no interior da mini-bacia considerada.

Os hidrogramas calculados e observados podem ser comparados nos locais correspondentes aos postos fluviométricos com dados. A avaliação é feita usando estatísticas usualmente utilizadas em modelagem hidrológica, como o coeficiente de eficiência de Nash-Sutcliffe (NS), coeficiente de eficiência dos logaritmos das vazões de Nash-Sutcliffe $\left(\mathrm{NS}_{\log }\right)$ e erro no Volume $(\Delta \mathrm{V})$.

\section{RESULTADOS E DISCUSSÃO}

Inicialmente são descritos os resultados da calibração do método de interpolação de chuva combinada de satélite e de pluviômetros. Posteriormente são descritos os resultados obtidos utilizando as fontes de dados de precipitação nas simulações utilizando o modelo hidrológico.

\section{Geração do campo de precipitação combinado}

Para calcular os parâmetros do modelo de interpolação CHUVSAT, foram definidos dois períodos (calibração e verificação). A etapa de calibração corresponde ao período de $1 / 3 / 2000$ a 31/12/2003 e a etapa de verificação corresponde ao período de $1 / 1 / 2004$ a 31/12/2006.

Para determinar o valor ideal do raio máximo $\left(\mathrm{R}_{\max }\right)$, o processo de otimização dos parâmetros foi repetido 14 vezes, utilizando dados do período de calibração, considerando valores de Rmax de $25 \mathrm{~km}$ até $200 \mathrm{~km}$, conforme a Tabela 3 . Esta mesma tabela mostra os valores dos demais parâmetros já

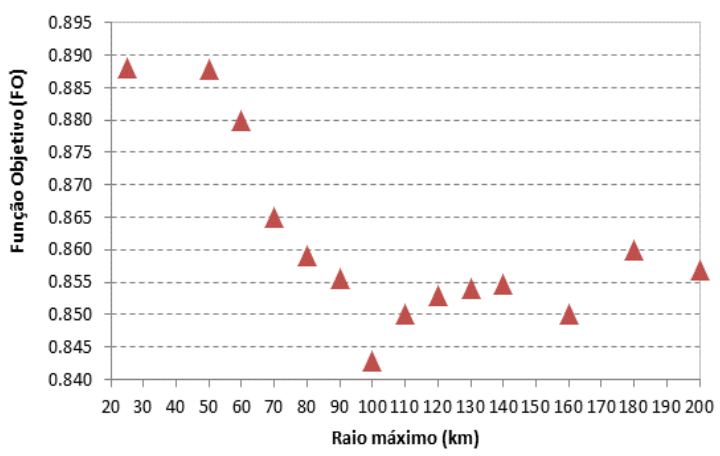

Figura 3 - Determinação do raio máximo $\left(\mathbf{R}_{\max }\right)$ com relação ao valor da função objetivo para o período de calibração 2000-2003 sobre a bacia do Rio Tocantins
Tabela 3 - Valores dos parâmetros do método de interpolação CHUVSAT para cada raio máximo sobre a bacia do Rio Tocantins no período de $2000-2003$

\begin{tabular}{|c|c|c|c|c|c|}
\hline $\begin{array}{c}\text { Rmax } \\
(\mathbf{k m})\end{array}$ & $\begin{array}{c}\text { alfa } \\
(\mathbf{\pm})\end{array}$ & $\begin{array}{c}\text { beta } \\
(\boldsymbol{\beta})\end{array}$ & $\begin{array}{c}\text { gamma } \\
(\boldsymbol{\gamma})\end{array}$ & $\begin{array}{c}\text { teta } \\
\mathbf{( \boldsymbol { \theta } )}\end{array}$ & $\mathbf{F}$ \\
\hline 25 & 238.25 & 16.28 & 0.80 & 0.43 & 0.888 \\
\hline 50 & 242.71 & 16.61 & 0.80 & 0.43 & 0.888 \\
\hline 60 & 197.29 & 28.38 & 0.85 & 0.78 & 0.880 \\
\hline 70 & 154.61 & 33.54 & 0.92 & 1.02 & 0.865 \\
\hline 80 & 187.23 & 54.50 & 0.99 & 1.21 & 0.859 \\
\hline 90 & 185.96 & 63.24 & 1.05 & 1.35 & 0.856 \\
\hline 100 & 236.18 & $\mathbf{5 4 . 1 1}$ & 1.14 & 1.40 & $\mathbf{0 . 8 4 3}$ \\
\hline 110 & 235.15 & 74.00 & 1.22 & 1.54 & 0.850 \\
\hline 120 & 176.39 & 53.01 & 1.28 & 1.61 & 0.853 \\
\hline 130 & 216.49 & 62.68 & 1.34 & 1.66 & 0.854 \\
\hline 140 & 189.05 & 46.57 & 1.43 & 1.71 & 0.855 \\
\hline 160 & 230.90 & 47.78 & 1.53 & 1.78 & 0.850 \\
\hline 180 & 241.00 & 43.45 & 1.61 & 1.84 & 0.860 \\
\hline 200 & 228.73 & 37.66 & 1.69 & 1.90 & 0.857 \\
\hline
\end{tabular}

otimizados, e o valor da função objetivo (Equação 4). A relação entre o valor de Rmax e a função objetivo FO é apresentada também na Figura 3. Observa-se que o valor mais baixo da função objetivo corresponde ao valor de $R \max =100 \mathrm{~km}$. Este valor é semelhante ao sugerido por Rozante et al. (2009) e por Vila et al. (2010) que adotaram um valor de raio máximo de busca de aproximadamente $70 \mathrm{~km}$ em seus algoritmos de combinação de dados.

Nesta condição os valores dos parâmetros $\gamma(1,14)$ e $\theta$ $(1,40)$ são relativamente próximos entre sim, enquanto os valores de $\alpha(236,18)$ e $\beta(54,11)$ são bastante diferentes. A diferença entre os valores dos parâmetros $\alpha$ (que pode ser entendido como um peso para o dado do pluviômetro) e $\beta$ (que pode ser entendido
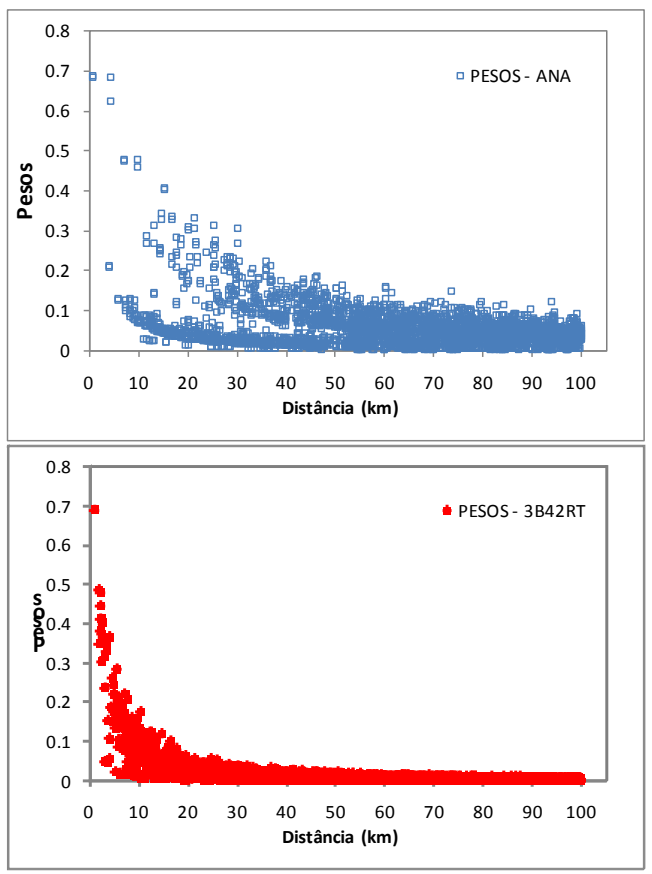

Figura 4 - Valores dos pesos calculados na etapa de calibração. a) Pesos em referencia com os postos pluviométricos; b) Pesos em referencia a os centros de grade de satélite TRMM 
a) PLUVIOMETROS-ANA

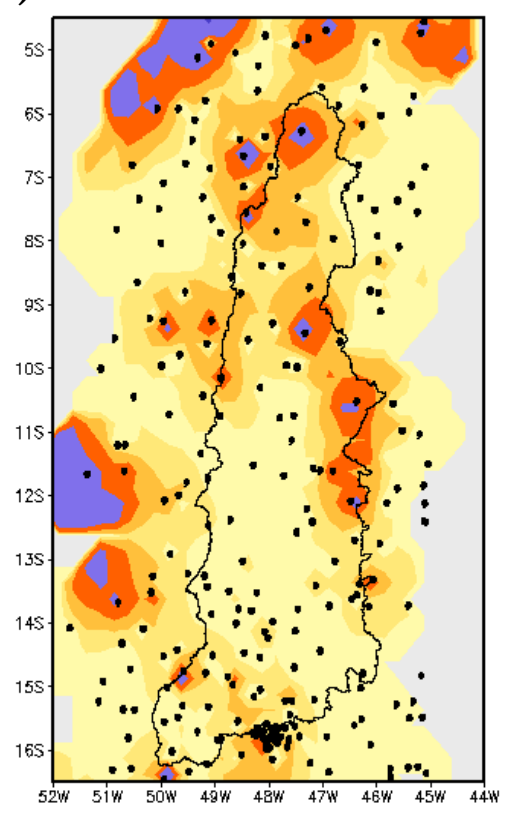

b)

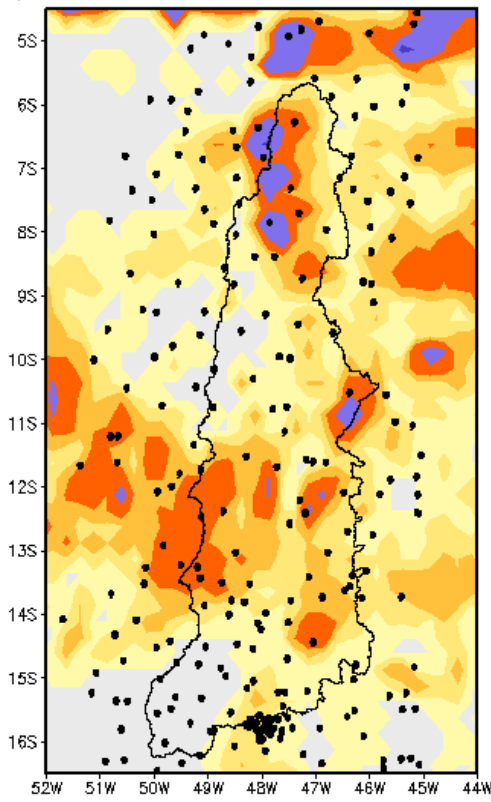

c) CHUVSAT

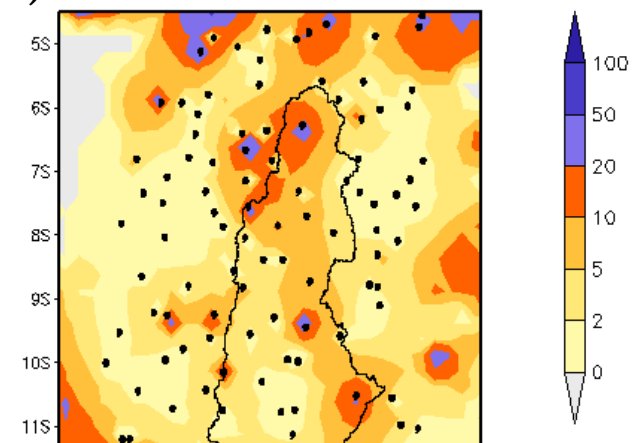

Figura 5 - Campos de precipitação sobre a região da bacia do rio Tocantins para o dia 1/1/2006. Esquerdo: Campo de precipitação interpolado com base aos postos pluviométricos. Médio: Campo de precipitação de TRMM-3B42RT. Direito: Campo de precipitação como resultado do modelo de interpolação CHUVSAT

como um peso para o dado de estimativa de chuva por satélite) mostra que o procedimento de interpolação otimizado daria um peso maior para cada um dos dados dos pluviômetros do que para cada um dos dados de satélite. A Figura 4 mostra os pesos de informações de pluviômetros (equação 2 e Figura 4a) e de informações de satélite (equação 3 e Figura 4b) em todo o processo de calibração. Observa-se que os pesos dos dados de pluviômetros são maiores para uma mesma distância.

A Figura 4 mostra também, que os pesos calculados pelos pluviômetros e pelo satélite TRMM-3B42RT, variam entre um valor próximo à zero até um valor próximo a 0,70 . O peso tende a decrescer com o aumento da distância, como é de se esperar de acordo com as equações 2 e 3.

Após a calibração, o método de interpolação combinada CHUVSAT foi aplicado para gerar estimativas de precipitação em uma região retangular envolvendo a bacia do rio Tocantins. A Figura 5 apresenta a chuva no dia $1 / 1 / 2006$, utilizando a interpolação considerando somente os dados dos pluviômetros (Figura 5a); utilizando somente os dados de satélite (Figura 5b); e utilizando o método CHUVSAT (Figura 5c).

Observa-se na Figura 5 que o campo de chuva interpolado pelo método combinado CHUVSAT apresenta algumas características da chuva obtida pelos pluviômetros e algumas características da chuva estimada por satélite. Na região central da bacia (entre 12 S e 13 S e $48 \mathrm{~W}$ e $49 \mathrm{~W}$ ), por exemplo, onde há baixa densidade de postos pluviométricos, o método de interpolação combinada (Figura 5c) apresenta estimativas de chuva mais altas do que o método baseado apenas nos dados dos pluviômetros (Figura 5a). Isto ocorre porque nesta região a estimativa de chuva por satélite apresenta valores mais altos do que os observados nos pluviômetros.
Para demonstrar o efeito da combinação de dados de satélite e de pluviômetros na interpolação, foram analisados os dados de chuva média ponderada em uma das sub-bacias de cabeceira. A Figura 6 apresenta os resultados na sub-bacia do rio Paranã, a montante do Posto Fluviométrico Ponte Paranã (Código 21600000). A Figura 6a mostra um gráfico das séries temporais de precipitação média nessa sub-bacia, em intervalo diário, no período de julho/2000 a dezembro/2000. A Figura 6b apresenta um gráfico de dispersão, em que os valores de chuva média estimada pelo método TRMM-3B42RT (apenas dados de satélite) e pelo método CHUVSAT (combinação de dados de satélite e pluviômetros), são comparados com os dados de chuva média estimada apenas com os dados de pluviômetros (ANA). A Figura 6b mostra que a dispersão dos dados de chuva estimados com base na estimativa combinada (CHUVSAT), é menor do que a dispersão dos dados de chuva estimada apenas com base no satélite (TRMM-3B42RT). Entretanto, é preciso lembrar que esta menor dispersão não significa, necessariamente, que a estimativa de chuva média com base no método CHUVSAT seja melhor do que a estimativa baseada apenas no satélite. $\mathrm{O}$ resultado da Figura 6b apenas mostra que a utilização dos dados de pluviômetros em combinação com os dados de satélite, permitiu criar uma série de dados de chuva mais semelhante à série baseada apenas nos dados de pluviômetros.

No período de tempo entre Janeiro/2000 e Dezembro/2003 (etapa de calibração), o coeficiente de correlação linear entre os dados de chuva média do método CHUVSAT e os dados de chuva média obtida apenas com base nos pluviômetros é de 0,97 . Neste mesmo período, este mesmo coeficiente é de 0,78 quando são comparados os dados de chuva média obtidos com o TRMM-3B42RT com os dados de chuva média obtidos com os 
a)

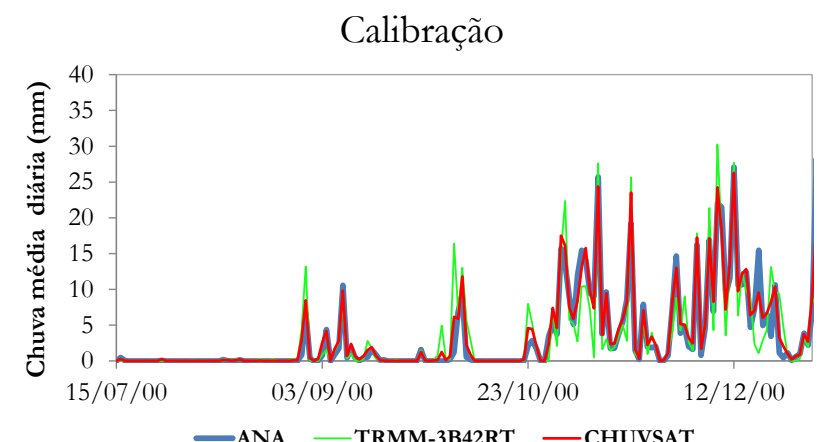

c)

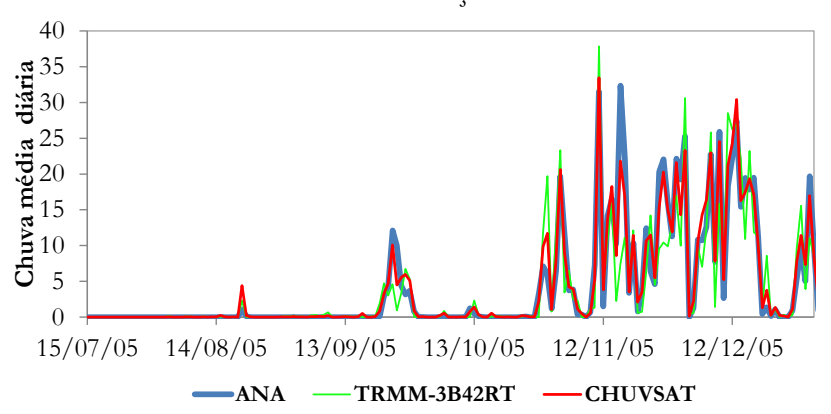

b)

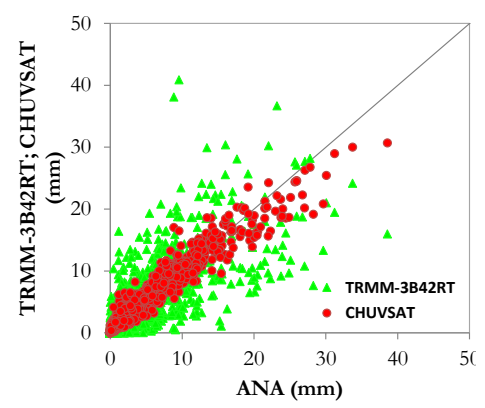

d)

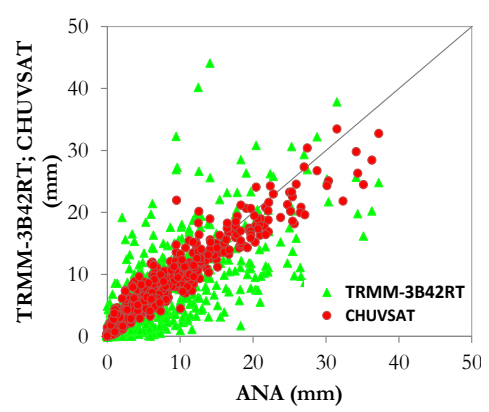

Figura 6 - Chuva média diária sobre a sub-bacia da Ponte Paranã $\left(30.000 \mathrm{~km}^{2}\right)$ para três fontes de chuva ANA, TRMM e CHUVSAT. Acima: Etapa de calibração; Abaixo: Etapa de verificação

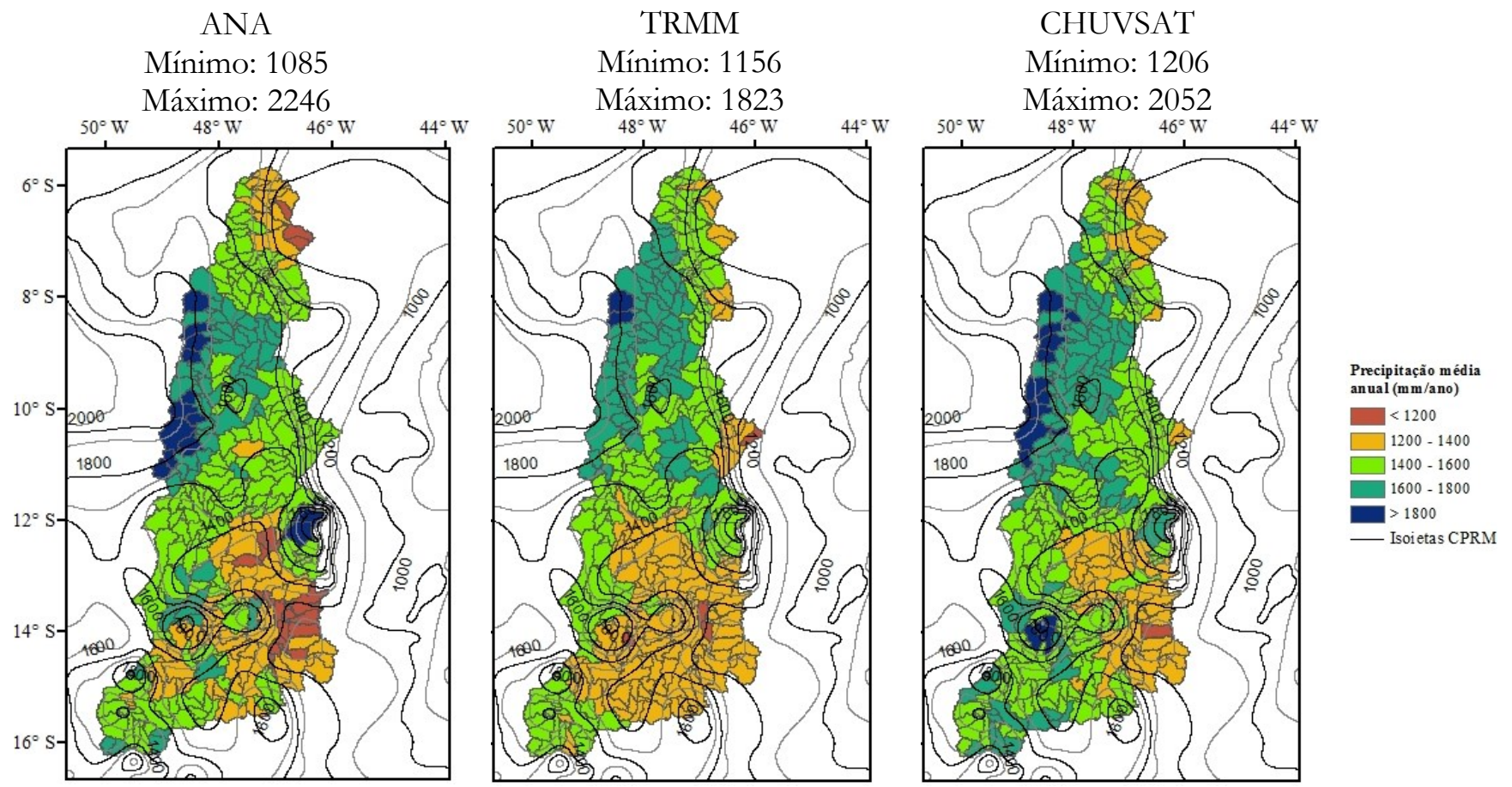

Figura 7 - Chuva média anual sobre as mini-bacias da discretização do modelo hidrológico para as fontes de chuva ANA, TRMM, CHUVSAT para o período de 2000-2006 
pluviômetros. Na etapa de verificação (período de Janeiro/2004 a Dezembro/2006), este mesmo padrão é mantido, conforme pode se observar nas Figura 6c e 6d.

Também foram mostrados em termos de chuva média anual calculada para cada mini-bacia para o período de 20002006 e comparados com as isoietas da base de dados do Serviço Geológico do Brasil para o período de 1977 a 2006 (PINTO et al., 2011), como está mostrado na Figura 7. Todas as fontes analisadas mostram uma diminuição da chuva de Noroeste para Sudeste da bacia. Os resultados mostram maiores semelhanças para ANA e CHUVSAT comparadas com as isoietas do CPRM e maior sub-estimativa para TRMM-3B42RT.

O campo de precipitação média anual calculada e mostrada na Figura 7 para CHUVSAT foram, também, comparados com os campos obtidos nos resultados do trabalho de Lourerio e Lisboa (2011). O campo de chuva média anual, com o método de interpolação de Thin Plate Spline aplicado nesse trabalho, foi mais similar com os campos de precipitação por CHUVSAT.

\section{Aplicação no modelo hidrológico MGB-IPH}

A avaliação do método CHUVSAT para a combinação de dados de satélite e pluviômetro também foi realizada com base nos resultados da aplicação do modelo hidrológico MGB-IPH para o período de 1998-2006. A bacia hidrográfica foi dividida em 375 mini-bacias e em 27 sub-bacias, conforme ilustrado na Figura 8.

A precipitação do produto TRMM-3B42RT foi composta por duas séries de precipitação, devido a que este produto está disponível apenas a partir do ano 2000 e o período de simulação hidrológica, neste trabalho, começa no ano 1998. Nesse sentido, a primeira série de precipitação por satélite é composta pelo produto TRMM-3B42 para o período de Jan/1998 - Fev/2000 e pelo produto TRMM-3B42RT para o período de Mar/2000 - Dez/2006. Porém, as duas séries foram juntadas em uma só para gerar a série de precipitação por satélite, aqui chamada de TRMM-3B42RT.

Inicialmente os parâmetros do modelo hidrológico foram calibrados com base nos dados de pluviômetros (ANA). Posteriormente, o modelo hidrológico foi aplicado com os dados de chuva estimados por satélite do TRMM-3B42RT e com os dados de chuva obtidos com o método de interpolação combinada, CHUVSAT, sem recalibrar o modelo.

A Figura 9 mostra os hidrogramas em quatro postos fluviométricos: Itacaja, Porto Real, Jacaré e Ponte Paranã durante o período de Set/2004- Set/2006. Observa-se que a variabilidade sazonal é bem representada pelas três fontes de precipitação. Porém, alguns picos máximos calculados não foram bem representados, como em Itacaja no dia 22/4/2006 e em Paranã em 20/12/2005, mostrando em ambos os casos

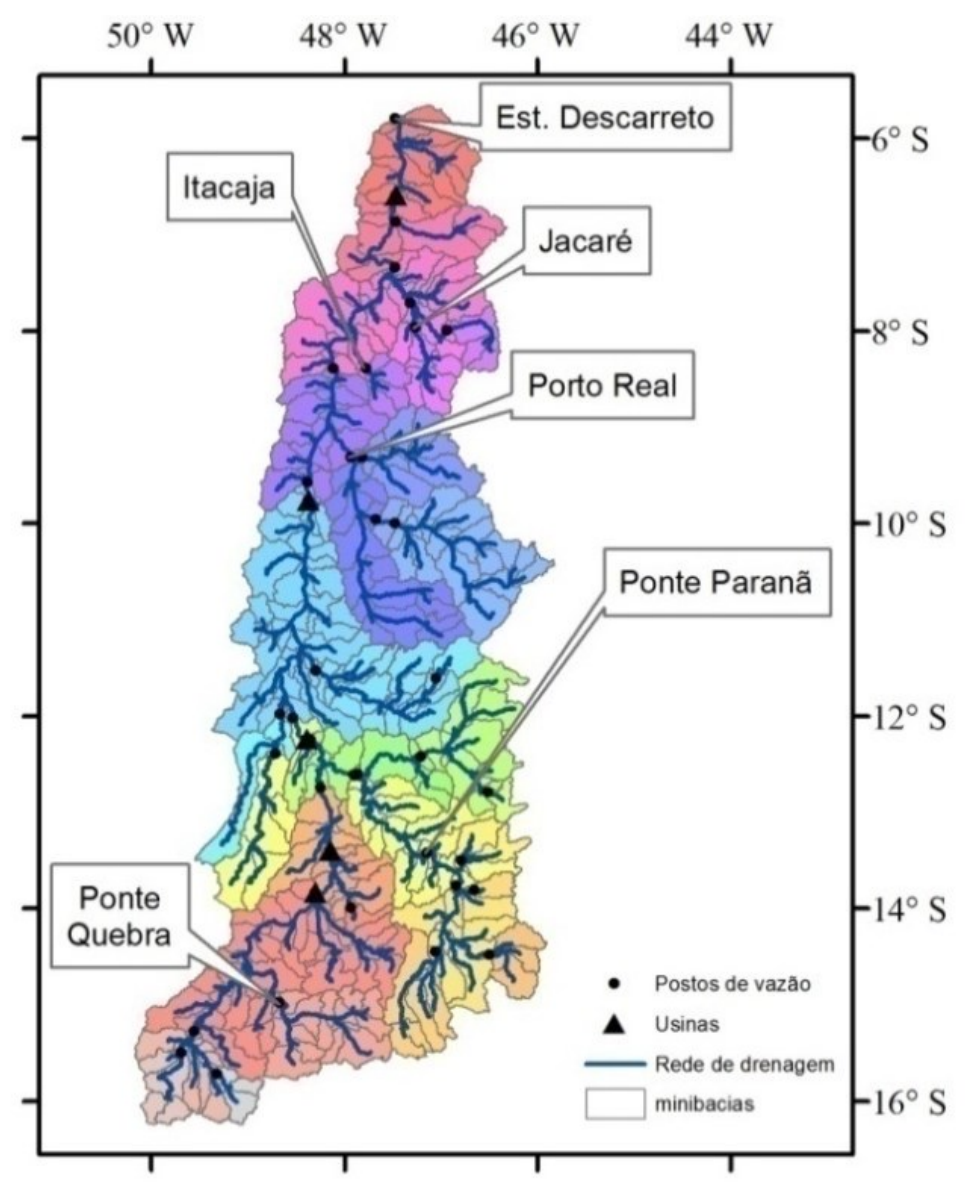

Figura 8 - Discretização da bacia em mini-bacias e sub-bacias para aplicação do modelo hidrológico MGB-IPH sobre a bacia do rio Tocantins 

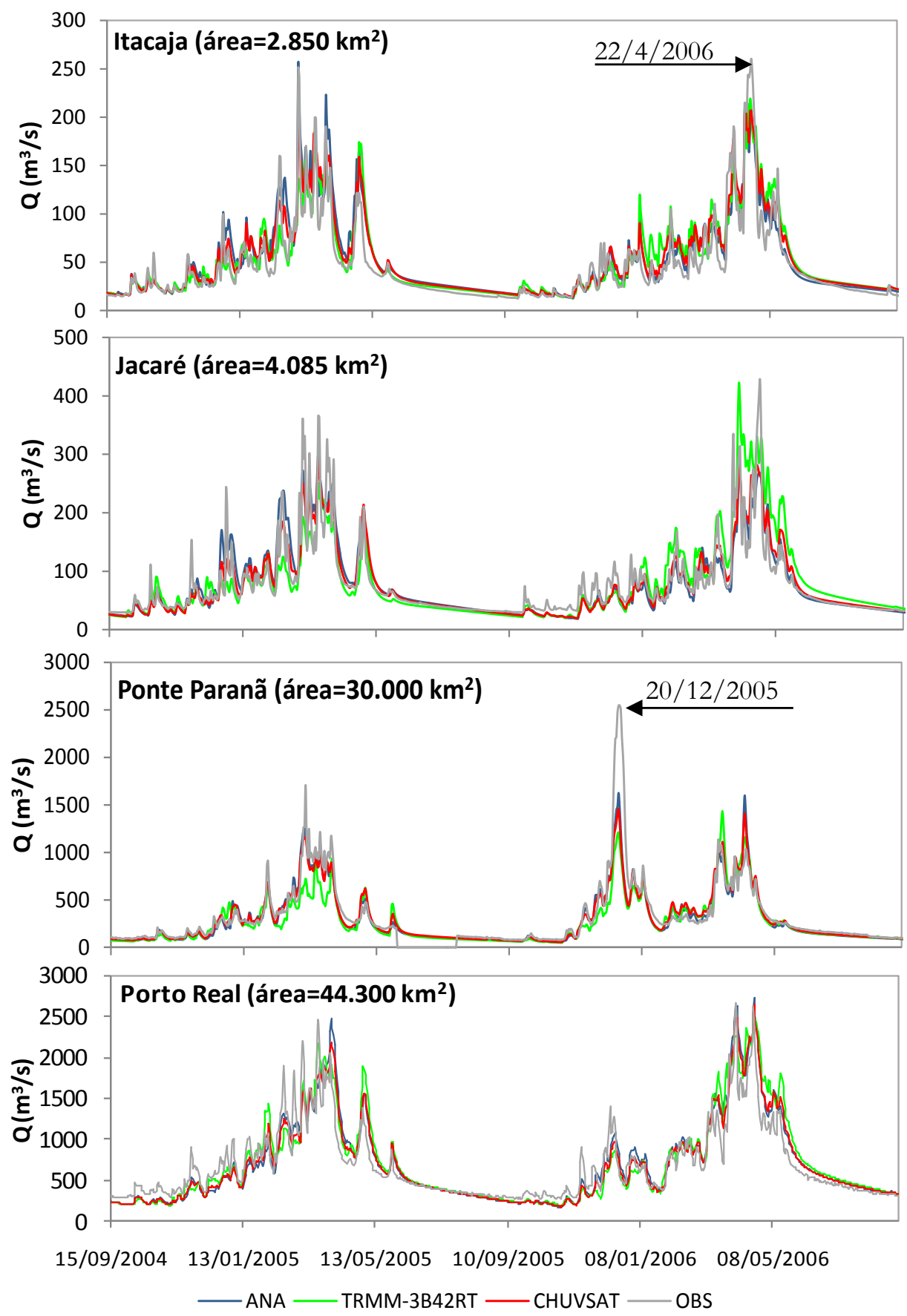

Figura 9 - Comparação dos hidrogramas de vazões diários observados e calculados, durante o período de setembro/2004 a setembro/2006, para quatro estações de controle, sobre a bacia do rio Tocantins

vazões máximas calculadas que ficaram subestimadas. Também foram encontradas diferenças no posto fluviométrico da Ponte Paranã, onde o hidrograma calculado apenas com os dados do TRMM-3B42RT resultou em uma sub-estimativa durante período úmido do ano 2005 e 2006.

A Tabela 4 mostra valores estatísticos como Nash-Sutcliffe (NS), Nash-Sutcliffe dos logaritmos da vazão $\left(\mathrm{NS}_{\mathrm{log}}\right)$ e Erro no Volume (dV) das 27 estações fluviométricas com dados de vazão observada na bacia do Rio Tocantins. Os valores marcados em negrito representam os valores dos testes estatísticos das estações que se mostram nos hidrogramas da Figura 9.

$\mathrm{Na}$ Tabela 4 é interessante observar, que as estatísticas, como o coeficiente de eficiência de Nash Sutcliffe, é melhor para CHUVSAT em quase todas as sub-bacias. A média do valor de NS de todos os postos fluviométricos é de 0,63 quando se usa os dados de chuva combinados (CHUVSAT) e de 0,60 quando se usa apenas os dados de chuva de pluviômetros. O mesmo ocorre com o valor do coeficiente de eficiência de Nash-Sutcliffe 
Tabela 4 - Coeficientes Estatísticos para os postos fluviométricos com as três fontes de precipitação em análises sobre a bacia do rio Tocantins

\begin{tabular}{|c|c|c|c|c|c|c|c|c|c|c|c|}
\hline \multirow[b]{2}{*}{ ITEM } & \multirow[b]{2}{*}{ ESTAÇÃO } & \multirow{2}{*}{$\begin{array}{c}\text { AREA } \\
\left(\mathrm{Km}^{2}\right)\end{array}$} & \multicolumn{3}{|c|}{ ANA } & \multicolumn{3}{|c|}{ TRMM-3B42RT } & \multicolumn{3}{|c|}{ CHUVSAT } \\
\hline & & & NS & $\mathrm{NS}_{\log }$ & dV & NS & $\mathrm{NS}_{\log }$ & $\mathrm{dV}$ & NS & $\mathrm{NS}_{\log }$ & $\mathrm{dV}$ \\
\hline 1 & Ponte rio preto & 881 & 0,55 & 0,76 & $-5,99$ & 0,42 & 0,68 & $-8,80$ & 0,58 & 0,61 & 18,86 \\
\hline 2 & Porto Alegre & 1803 & 0,01 & $-0,27$ & 3,40 & $-0,33$ & $-0,30$ & 16,18 & $-0,05$ & $-0,12$ & 13,05 \\
\hline 3 & Jaragua & 1983 & 0,56 & 0,75 & $-10,83$ & 0,03 & 0,13 & $-50,26$ & 0,64 & 0,78 & $-16,32$ \\
\hline 4 & Itacaja & 2849 & 0,61 & 0,72 & 22,55 & 0,66 & 0,76 & 16,75 & 0,73 & 0,80 & 14,71 \\
\hline 5 & Fazenda Veneza & 2859 & 0,23 & $-1,33$ & $-1,91$ & $-0,05$ & $-0,92$ & 10,02 & 0,33 & $-1,03$ & 0,98 \\
\hline 6 & Cachoeira & 2933 & 0,47 & 0,46 & $-9,95$ & 0,23 & $-0,10$ & $-38,86$ & 0,39 & 0,18 & $-34,88$ \\
\hline 7 & Uruana & 3695 & 0,64 & 0,81 & 3,61 & 0,51 & 0,62 & $-19,86$ & 0,75 & 0,84 & $-0,85$ \\
\hline 8 & Alvorada Norte & 3787 & 0,47 & 0,59 & 7,82 & 0,50 & 0,57 & $-4,69$ & 0,55 & 0,66 & $-0,61$ \\
\hline 9 & Jacare & 4085 & 0,49 & 0,73 & 8,86 & 0,64 & 0,75 & $-1,20$ & 0,75 & 0,82 & 1,59 \\
\hline 10 & Fazenda Farinha & 5176 & 0,33 & $-0,38$ & $-18,63$ & 0,30 & 0,28 & $-6,25$ & 0,36 & $-0,03$ & $-15,94$ \\
\hline 11 & Flores de goias & 7288 & 0,58 & 0,80 & 7,48 & 0,38 & 0,59 & $-44,22$ & 0,78 & 0,85 & $-13,37$ \\
\hline 12 & Colonha & 8741 & 0,82 & 0,68 & 10,92 & 0,65 & 0,63 & $-5,34$ & 0,83 & 0,68 & 3,94 \\
\hline 13 & Doisir maos & 9546 & 0,63 & 0,74 & 15,06 & 0,56 & 0,78 & $-5,19$ & 0,67 & 0,80 & 5,85 \\
\hline 14 & Goiatins & 10098 & 0,70 & 0,76 & 1,07 & 0,63 & 0,69 & $-8,41$ & 0,82 & 0,80 & $-7,34$ \\
\hline 15 & Ceres & 10668 & 0,68 & 0,86 & 5,22 & 0,32 & 0,50 & $-20,54$ & 0,68 & 0,85 & 8,23 \\
\hline 16 & Ponte Quebra Linha & 11275 & 0,74 & 0,85 & 3,71 & 0,44 & 0,59 & $-22,60$ & 0,61 & 0,80 & 24,17 \\
\hline 17 & Rio da palma & 12992 & 0,48 & 0,62 & 2,61 & 0,31 & 0,18 & $-25,32$ & 0,52 & 0,58 & $-19,46$ \\
\hline 18 & Jacinto & 13938 & 0,82 & 0,58 & 10,23 & 0,62 & 0,54 & $-2,38$ & 0,81 & 0,57 & 6,11 \\
\hline 19 & Fazenda Lobeira & 14517 & 0,75 & 0,85 & 9,02 & 0,42 & 0,71 & 7,32 & 0,69 & 0,79 & 16,83 \\
\hline 20 & Jatobá & 17076 & 0,49 & 0,25 & $-5,28$ & 0,41 & 0,04 & $-20,88$ & 0,55 & 0,21 & $-16,59$ \\
\hline 21 & Barra Palma & 17989 & 0,66 & 0,65 & 7,91 & 0,50 & 0,64 & $-12,52$ & 0,69 & 0,74 & $-9,63$ \\
\hline 22 & Novo Acordo & 18187 & 0,55 & 0,26 & $-7,68$ & 0,40 & 0,03 & $-22,10$ & 0,56 & 0,23 & $-16,98$ \\
\hline 23 & Nova Roma & 22774 & 0,80 & 0,89 & 2,56 & 0,52 & 0,77 & $-17,08$ & 0,78 & 0,88 & $-4,97$ \\
\hline 24 & Ponte Parana & 29791 & 0,86 & 0,91 & $-0,89$ & 0,60 & 0,82 & $-12,09$ & 0,85 & 0,92 & $-1,39$ \\
\hline 25 & Montante Barra Palma & 40526 & 0,71 & 0,72 & $-4,68$ & 0,51 & 0,66 & $-16,23$ & 0,72 & 0,73 & $-6,39$ \\
\hline 26 & Porto Real & 44293 & 0,81 & 0,83 & 6,70 & 0,68 & 0,76 & $-3,34$ & 0,83 & 0,85 & 0,90 \\
\hline \multirow[t]{4}{*}{27} & Parana & 58568 & 0,65 & 0,66 & $-7,74$ & 0,44 & 0,60 & $-21,32$ & 0,62 & 0,66 & $-14,96$ \\
\hline & & Mínimo & 0,01 & $-1,33$ & $-18,63$ & $-0,33$ & $-0,92$ & $-50,26$ & $-0,05$ & $-1,03$ & $-34,88$ \\
\hline & & Médio & 0,60 & 0,55 & 2,04 & 0,42 & 0,44 & $-12,56$ & 0,63 & 0,57 & $-2,39$ \\
\hline & & Máximo & 0,86 & 0,91 & 22,55 & 0,68 & 0,82 & 16,75 & 0,85 & 0,92 & 24,17 \\
\hline
\end{tabular}

dos logaritmos das vazões (NSlog), que é de 0,57 no caso em que é usado o método de combinação CHUVSAT e de 0,55 quando são usados apenas dados de chuva de pluviômetros.

A tabela 4 mostra também que o valor do erro de volume tende a aumentar um pouco quando são utilizados dados da estimativa combinada de chuva CHUVSAT. A mesma tabela mostra também que quando são usadas apenas as estimativas de chuva por satélite (TRMM-3B42RT), todas as estatísticas são piores. O NS cai de 0,60 para 0,42 e o erro de volume passa de $+2,04$ para $-12,56$. Este último resultado explica, em parte, porque o método de chuva combinada CHUVSAT apresenta erro de volume negativo, em média. Aparentemente, a estimativa de chuva por satélite nesta região conduz a uma subestimativa da chuva média, se comparada com a chuva de postos pluviométricos. Finalmente, os resultados apresentados na Tabela 4, indicam que em média há um ganho quando são incorporadas estimativas de chuva por satélite a um método de interpolação de dados de chuva.

A Figura 10 mostra o coeficiente estatístico de NashSutcliffe onde se mostra o ganho da fonte de CHUVSAT sobre as outras duas fontes de precipitação ANA e TRMM-3B42RT de forma localizada. Os valores de NS para os dados com TRMM-3B42RT, atingiram o valor de 0,68. Enquanto que, para as fontes ANA e CHUVSAT a eficiência atingiu o valor de 0,86.

Os resultados com CHUVSAT são melhores do que os resultados usando chuva de pluviômetros em bacias de cabeceira, as quais são localizadas no Sul e Nordeste, onde a densidade de postos pluviométricos é inferior. Porém, na estação Ponte Quebra Linha (20050000) sub-bacia próxima a varias estações pluviométricas (Vide Figura 1), o valor de NS para os dados com CHUVSAT se mostrou inferior comparado com ANA. Nessa estação aparentemente existe uma sub-estimativa da precipitação com dados de CHUVSAT que se mostra no valor do erro no volume $(\mathrm{dV}=+24,17)$, que piorou as vazões calcula- 

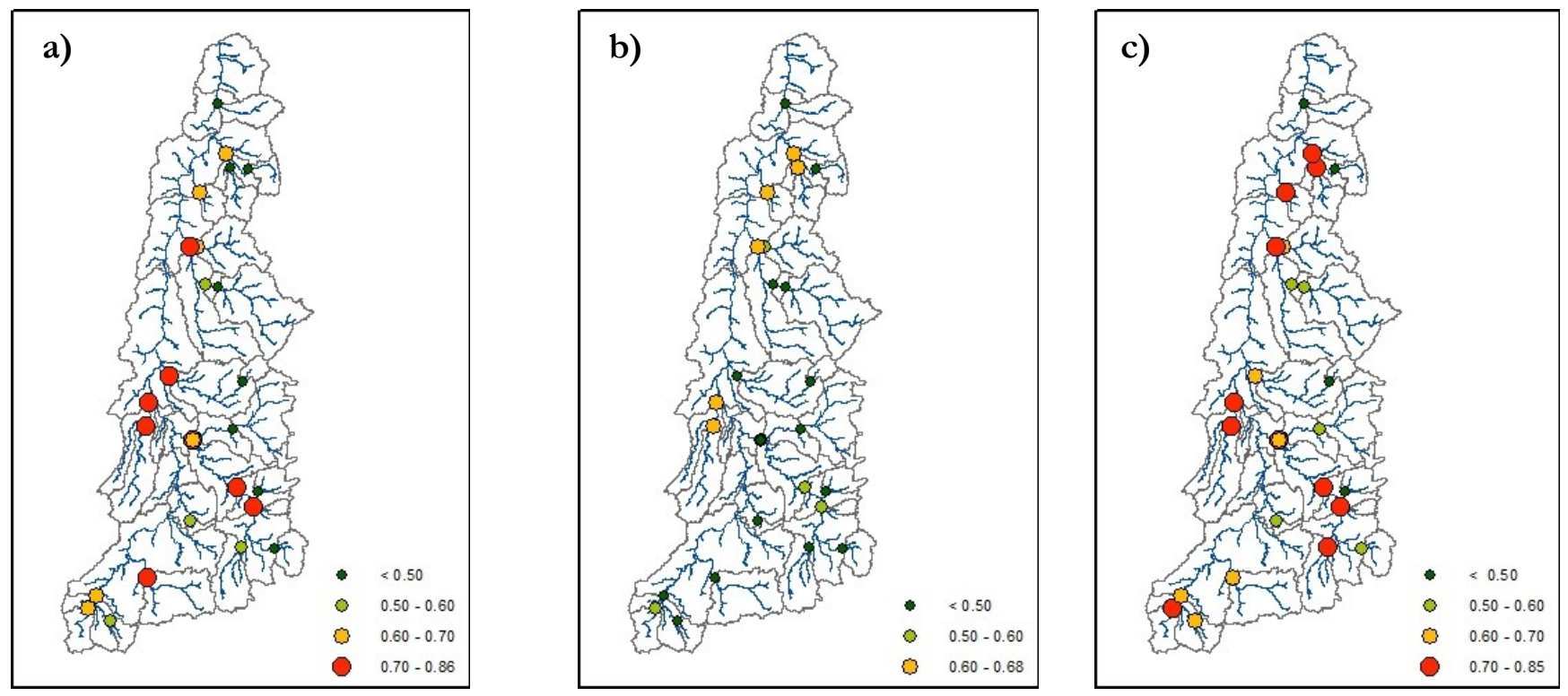

Figura 10 - Comparação entre coeficiente de Nash-Sutcliffe para a bacia do Rio Tocantins. a) ANA; b) TRMM-3B42RT; c) CHUVSAT

\section{Área de drenagem $\left(\mathrm{km}^{2}\right)$}

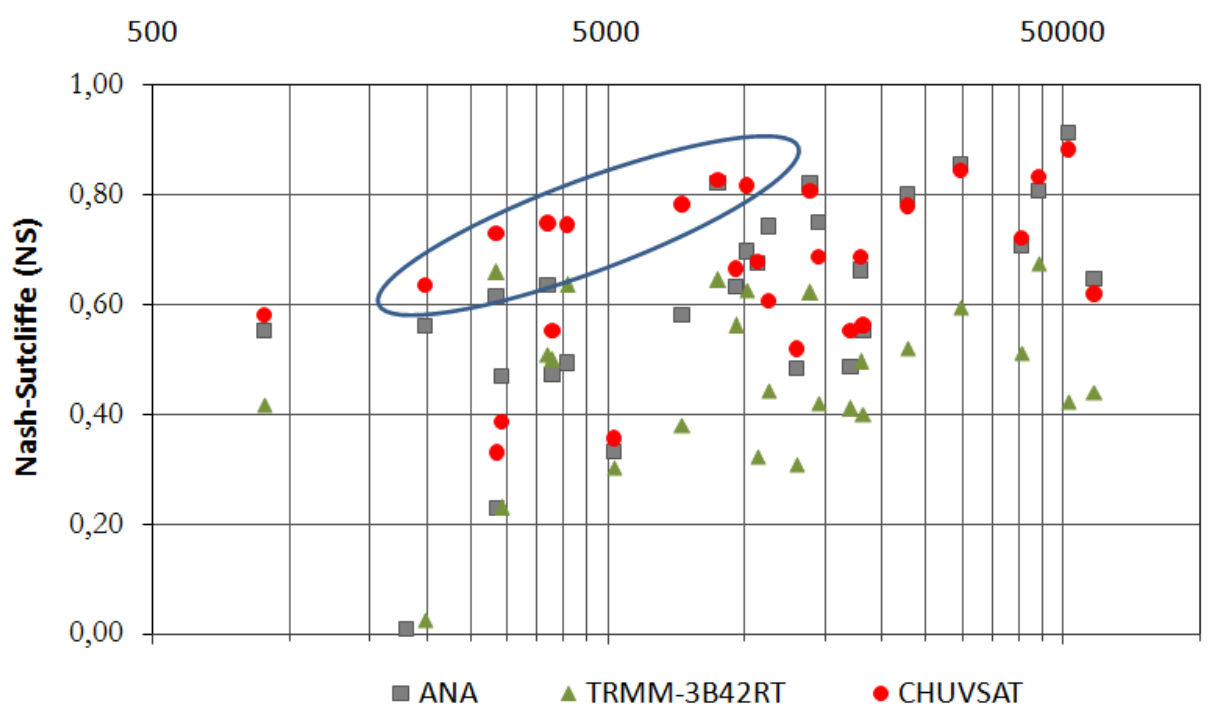

Figura 11 - Coeficiente de eficiência de Nash-Sutcliffe (NS) em função da área de drenagem para a bacia do rio Tocantins

das, sobretudo nos valores máximos, onde o valor de eficiência de Nash- Sutcliffe é mais sensível. Acredita-se que com uma calibração com base nos dados de CHUVSAT, os valores de eficiência podem melhorar nessa estação.

A Figura 11 mostra o valor do coeficiente de eficiência de Nash-Sutcliffe em função da área de drenagem de cada posto fluviométrico, nas três simulações realizadas. Os quadrados de cor cinza indicam os valores de NS na simulação com chuva de postos pluviométricos. Os pontos vermelhos indicam os valores de NS na simulação com chuva combinada CHUVSAT, e os triângulos verdes indicam os resultados com a chuva estimada por satélite, sem correção. Em geral, é importante observar que há uma tendência de aumento do valor de NS com o aumento da área de drenagem.

$\mathrm{Na}$ mesma Figura 11, observa-se que nas bacias com maior área de drenagem o valor de NS é semelhante, quando são usados dados de chuva apenas de pluviômetro ou de combinação CHUVSAT. Entretanto, é importante destacar que, numa faixa de áreas de drenagem entre aproximadamente $2.000 \mathrm{~km}^{2} \mathrm{e}$ aproximadamente $10.000 \mathrm{~km}^{2}$, os resultados obtidos utilizando CHUVSAT são consistentemente superiores aos obtidos utilizando apenas os dados de pluviômetros. Finalmente, a Figura 11 também mostra que os valores de NS obtidos com a chuva do TRMM-3B42RT são mais baixos do que os valores de NS 
obtidos com a chuva dos pluviômetros (ANA) e com o método combinado (CHUVSAT).

\section{CONCLUSÃO}

Neste trabalho é apresentado um método de combinação de dados de chuva de pluviômetros e de satélite através de interpolação ponderada pela distância e pelo tipo de informação. Considerando que os pluviômetros estão disponíveis em pontos aleatórios e que a informação de chuva de satélite, está disponível sobre os pontos de uma grade regular. Esse novo campo de chuva é avaliado como dado de entrada a um modelo hidrológico distribuído.

Uma calibração do método de combinação também é apresentada, a partir da maximização da correlação entre os dados interpolados e os dados observados em postos pluviométricos. A chuva média anual calculada com o método de combinação de dados de satélite e pluviômetros mostrou concordância com o mapa de isoietas produzido pela CPRM, embora as estimativas de chuva de satélite (TRMM-3B42RT) apresentem uma subestimativa na região, especialmente no Noroeste da bacia.

Os resultados sugerem que a combinação dos dados de chuva de satélite com os dados de chuva de postos pluviométricos permitem criar um conjunto de dados útil para aplicações em hidrologia. Na avaliação baseada na comparação dos hidrogramas, obtidos com um modelo chuva-vazão com dados observados de vazão em postos fluviométricos, os melhores resultados médios foram encontrados quando foram utilizados os dados de chuva, obtidos pelo método de interpolação CHUVSAT. Este resultado foi mais evidente em bacias cuja área de drenagem tem entre 2.000 e $10.000 \mathrm{~km}^{2}$.

O método de combinação de dados de precipitação proposto é relativamente simples e pode ser generalizado para outras fontes de observação. Por exemplo, poderiam ser explorados os dados de outros produtos de estimativa de precipitação a partir de satélites, como CMORPH ou PERSIANN. Da mesma forma, acredita-se que poderiam ser utilizados outros tipos de dados de pluviômetros, como os dados de pluviômetros automáticos das redes de telemetria, em que os dados são disponibilizados em intervalo de tempo horário, ou até menor.

Acredita-se que os métodos de combinação de dados de chuva de satélite e de pluviômetros continuem sendo relevantes no futuro, apesar das melhorias nas estimativas de satélite que são esperadas com as tecnologias mais recentes adotadas em novas missões espaciais.

\section{REFERÊNCIAS}

AGENCIA NACIONAL DE ENERGIA ELÉTRICA, Análise de consistência de dados pluviométricos. Rep. Brasília:FUB/ FNB, 1999. 71 p.

ARAUJO, A. N.; GUETTER, A. K. Validação da Chuva Estimada por Satélite "CMORPH" na modelagem Hidrológica do Alto Iguaçu. Revista Brasileira de Recursos Hídricos, v. 12, p. 189-198, 2007.
BEHRANGI, A.; KHAKBAZ, B.; J., T. C.; AGHAKOUCHAK, A.; HSU, K.; SOROOSHIAN, S. Hydrologic evaluation of satellite precipitation products over a mid-size basin. Journal of Hydrology, v. 397, p. 225-237, 2011.

BUARQUE, D. C.; PAIVA, R. C.; CLARKE, R. T.; MENDES., C. A. A comparison of Amazon rainfall characteristics derived from TRMM, CMORPH and the Brazilian national rain gauge network. Journal of Geophysical Research Atmospheres, v.116, n.D19, Oct. 2011. D19105, doi:10.1029/2011JD01606D19105.

CHIANG, Y. M.; HSU, K. L.; CHANG, F. J.; HONG, Y.; SOROOSHIAN., S. Merging multiple precipitation sources for flash flood forecasting. Journal of Hydrology, v. 340, n. 3-4, p. 183-196, 2007.

CLARKE, R. T.; BUARQUE., D. C. Statistically combining rainfall characteristics estimated from remote-sensed and rain gauge data sets in the Brazilian Amazon-Tocantins Basins. Journal of Geophysical Research Atmospheres, v.118, n. 14, July, p.7467-7480, 2013. doi: 10.1002/jgrd.50545.

COLLISCHONN, B.; ALLASIA, D.; COLLISCHONN, W.; TUCCI., C. E. Desempenho do satélite TRMM na estimativa de precipitação sobre a bacia do Paraguai Superior. Revista Brasileira de Cartografia, v. 59, p. 93-99, 2007.

COLLISCHONN, B.; COLLISCHONN, W.; TUCCI,.C. E. M. Daily hydrological modeling in the Amazon basin using TRMM rainfall estimates. Journal of Hydrology, v. 360, n. 1-4, p. 207-216, 2008..

COLLISCHONN, W.; TUCCI, C. E. Simulação Hidrológica de grandes bacias. Revista Brasileira de Recursos Hidricos, v. 6, n. 1, p. 95-118, 2001.

DINIZ, L. S. Calibração de modelos hidrológicos. In: GALVÃO, C.O.; VALENÇA, M.J.S. (Org.). Sistemas Inteligentes: aplicaçôes a recursos hidricos e ciências ambientais. Porto Alegre: ABRH-UFRGS, 2004, p. 151-166.

DINKU, T.; CONNOR, S.; CECCATO, P. Comparison of CMORPH and TRMM-3B42 over Mountainous Regions of Africa and South America. In: GEBREMICHAEL, M.; HOSSAIN, F. Satellite Rainfall Applications for Surface Hydrology. Berlin: Springer Netherlands, 2010. p. 193-204.

DUAN, Q.; SOROOSHIAN, S.; GUPTA, V. Effective and efficient global optimization for conceptual rainfall-runoff models. Water Resources Research, v. 28, p. 1015-1031, 1992.

EINFALT, T.; MICHAELIDES, S. Quality control of precipitation data. In: MICHAELIDES, S. (Org.). Precipitation: Advances in Measurement, Estimation and Prediction. Berlin: Springer Berlin Heidelberg, 2008. p. 101-126.

FAN, F. M.; COLLISCHONN, W.; BUARQUE, D. C.; PAIVA, 
Jiménez e Collischonn: Método de combinação de dados de precipitação estimados por satélite e medidos em pluviômetros para a modelagem hidrológica

R. C.; KAYSER, R. Manual ArcHydro para aplicação do modelo MGB-IPH, Versão 1.2. Porto Alegre: IPH-UFRGS, 2009.

FAN, F. M.; COLLISCHONN, W.; BUARQUE, D. C.; PAIVA, R. C.; KAYSER, R. Manual de Prepro-MGB para aplicação do modelo MGB-IPH, versão 4.1. Porto Alegre: IPH-UFRGS. 2010.

GETIRANA, A.C.V.; ESPINOZA, J.C.V.; RONCHAIL, J.; FILHO, O.C. ROTUNNO. Assessment of different precipitation datasets and their impacts on the water balance of the Negro River basin. Journal of Hydrology, v. 404, p. 304-322, 2011.

HONG, Y.; HSU, K. L.; SOROOSHIAN, S.; GAO, X. Precipitation Estimation from Remotely Sensed Imagery Using an Artificial Neural Network Cloud Classification System. J. Appl. Meteor., v. 43, n. 12, p. 1834-1853, 2004.

HOU, A. Y.; G., SKOFRONICK J.; KUMMEROW, C. D.; SHEPHERD, J. M. Global Precipitation Measurement. In: MICHAELIDES, S. (Org.). Precipitation: Advances in Measurement, Estimation and Prediction. Berlin: Springer-Verlag Berlin Heidelberg, 2008. p. 131-169.

HUFFMAN, G.J.; ADLER, R.F.; BOLVIN, D.T.; GU, G.; NELKIN, E.J.; BOWMAN, K.P.; HONG, Y.; STOCKER, E.F.; WOLFF, D.B. The TRMM Multisatellite Precipitation Analysis (TMPA): Quasi-global, multiyear, combined-sensor precipitation estimates at fine scales. Journal of Hydrometeorology, v. 8, n. 1, p. 38-55, 2007.

HUGHES, D. A. Comparison of satellite rainfall data with observations from gauging station networks. Journal of Hydrology, v. 327, n. 3-4, p. 399-410, 2006.

LENSKY, I. M.; LEVIZZANI, V. Estimation of precipitation from space-based platforms. In: MICHAELIDES, S. (Org.). Precipitation: Advances in Measurement, Estimation and Prediction. Berlin: Springer-Verlag Berlin Heidelberg, 2008. p. 195-217.

LOURERIO, G. E.; LISBOA, E. G. Comparação dos métodos de interpolação espacial aplicados a dados pluviométricos da região hidrográfica Tocantins-Araguaia. In: SIMPÓSIO BRASILEIRO DE RECURSOS HÍDRICOS, XIX., 2011, Maceió. Anais.... Maceió: ABRH, 2011.

ORGANIZAÇÃO METEOROLÓGICA MUNDIAL. Guide to Hydrological Practices: Data Acquisition and Processing analysis, forecasting and other applications. Geneve, 1994. 739 p.

PAIVA, R. C.; BUARQUE, D. C.; COLLISCHONN, W.; SORRIBAS, M.; ALLASIA, D.; MENDES, C. A.; TUCCI, C. E.; BONNET, M. P. Using TRMM rainfall estimates in hydrological and hydrodynamic modelling of the Amazon Basin. LAHS-AISH Publication, v. 343, p. 72-77, 2011.

PAN, M.; LI, H.; WOOD, E. Assessing the skill of satellite-based precipitation estimates in hydrologic applications. Water Resources
Research, v. 46, n. 9, 2010. doi: 10.1029/2009WR008290W09535.

PEREIRA F. A., J.; CARBONE, R. E.; JANOWIAK, J. E.; ARKIN, P.; JOYCE, R.; HALLAK, R.; RAMOS, C. G.M. Satellite Rainfall Estimates Over South America - Possible Applicability to the Water Management of Large Watersheds. JAWR A Journal of the American Water Resources Association, v. 46, n. 2, p. $344-360,2010$.

QUIROZ, J. K.; COLLISCHONN, W.; LAVADO, C. W. Modelización hidrológica usando estimaciones de lluvia por satélite en la cuenca del río Huallaga. Revista Peruana Geo-atmosférica RPGA, v. 3, p. 51-62, 2011.

QUIROZ, J. K.; MELO, TIRZAH; LOUZADA, JOSÉ ANTÔNIO. Uso de dados de precipitação obtidos por sensoriamento remoto aplicado em um modelo agro-hidrológico. Irriga, Botucato, v. 18, p. 496-508, 2013.

ROZANTE, J. R.; MOREIRA, D. S.; GONCALVES, L. G.; VILA, D. A. Combining TRMM and Surface Observations of Precipitation: Technique and Validation over South America. Wea. Forecasting, v. 25, n. 3, p. 885-894, 2010.

SALDANHA, C. B.; DA PAZ, A. R.; ALLASIA, D.; COLLISCHONN, W.; BARRERA, D. Avaliação da Chuva do hidroestimador para modelagem hidrológica na região da bacia do Rio Grande. In: SIMPÓSIO BRASILEIRO DE RECURSOS HÍDRICOS, XVII., 2007, São Paulo. Anais.... São Paulo, 2007.

SCOFIELD, G. B.; VENDRAME, I. Avaliação da Técnica de Estimativa de Precipitação GPI Sobre a Área de Abrangência do Radar de Bauru, SP. Revista Brasileira de Recursos Hídricos, v. 8, n. 4, p. 69-85, 2003.

PINTO, E. J. de A.; AZAMBUJA, A. M. S. de; FARIAS, J. A. M.; SALGUEIRO, J. P. B.; PICKBRENNER, K. (Coords.). Atlas pluviométrico do Brasil: isoietas mensais, isoietas trimestrais, isoietas anuais, meses mais secos, meses mais chuvosos, trimestres mais secos, trimestres mais chuvosos. Brasília: CPRM, 2011. 1 DVD. Escala 1.5:000.000. Equipe Executora: Da Costa, Margarida Regueira; Dantas, Carlos Eduardo de Oliveira; Melo, De Azambuja, Andressa Macêdo Silva; Denise Christina de Rezende; Do Nascimento, Jean Ricardo da Silva; Dos Santos, André Luis M. Real; Farias, José Alexandre Moreira; Machado, Érica Cristina; Marcuzzo, Francisco Fernando Noronha; Medeiros, Vanesca Sartorelli; Rodrigues, Paulo de Tarso R.; Weschenfelder, Adriana Burin; Sistema de Informação Geográfica-SIG - versão 2.0 atualizada em novembro/2011; Programa Geologia do Brasil; Levantamento da Geodiversidade. Disponível em: < http:// www.cprm.gov.br/publique/media/Isoietas

_Totais_Anuais_1977_2006.pdf>.Acesso em: 1 set. 2014.

STAMPOULIS, D.; ANAGNOSTOU, E. N. Evaluation of Global Satellite Rainfall Products over Continental Europe. J. Hydrometeor, v. 13, n. 2, p. 588-603, Jan. 2012. 
SU, F.; GAO, H.; HUFFMAN, G.J.; LETTENMAIER, D.P. Potential utility of the real-time TMPA-RT precipitation estimates in streamflow prediction. Journal of Hydrometeorology, v. 12, n. 3, p. 444-455, 2011.

SUMNER, G. Precipitation Proccess and Analysis. Chichester, UK: Jhon Wiley \& Sons Ltd., 1998.

VICENTE, G. A.; SCOFIELD, R. A.; MENZEL, W. P. The Operational GOES Infrared Rainfall Estimation Technique. Bull. Amer. Meteor. Soc., v. 79, n. 9, p. 1883-1898, 1998.

VILA, DANIEL A.; DE GONCALVES, LUIS GUSTAVO G.; TOLL, DAVID L.; ROZANTE, JOSE ROBERTO. Statistical Evaluation of Combined Daily Gauge Observations and Rainfall Satellite Estimates over Continental South America. J. Hydrometeor, v. 10, n. 2 , p. $533-543,2009$.

WOLDEMESKEL, F. M.; SIVAKUMAR, B.; SHARMA, A. Merging gauge and satellite rainfall with specification of associated uncertainty across Australia. Journal of Hydrology, v. 499, p. 167176, 2013. 